\title{
Determination of the resonance frequency - thickness relation based on the ambient seismic noise records from Upper Silesia Coal Basin
}

Maciej Jan Mendecki, Barbara Bieta, Mateusz Mycka
Department of Applied Geology, Faculty of Earth Sciences, University of Silesia, Bedzinska 60, 41-200 Sosnowiec maciej.mendecki@us.edu.pl

\begin{abstract}
In this paper the Horizontal-to-Vertical Spectral Ratio (HVSR) method and seismic data were applied to evaluate the resonance frequency - thickness relation. The HVSR method was used to estimate the parameters of site effects: amplification and resonance frequency from seismic noise records. The seismic noise was generated by artificial source occurring in Upper Silesia Coal Basin (UBSC), Poland, such as: traffic, industry, coal plants etc. The survey points were located near the Faculty of Earth Sciences in Sosnowiec, Bytom and Chorzow. Based on Albarello's statistical test the observed H/V maxima was confirmed or rejected. Resonance frequencies were compared with available thicknesses of soft layer obtained by seismic survey (Mendecki 2012). Finally, the estimated resonance frequency - thickness relation for UBSC area showed quite similar power function coefficients as those obtained by other authors.
\end{abstract}

Key words: HVSR method, Albarello test, site effects, Upper Silesia Coal Basin

DOI: $10.2478 / \operatorname{ctg}-2014-0011$

Received: $30^{\text {th }}$ June, 2014

Accepted: $4^{\text {th }}$ September, 2014

\section{Introduction}

The seismic noise is a ubiquitous seismic noise that propagate through surface layers, which are observed in the seismograms as small deflection of amplitudes. The frequency of these oscillations depends on the source that generates them. In a simple way, the ambient seismic noise can be divided into two types: microseisms - generated by natural sources (e.g. storm, sea waves) with long period ( $>1 \mathrm{~s})$ and microtremors (cultural noise) - generated by artificial sources (e.g. industry, traffic) with short period $(<1$ s) (Nakamura 1989). However, the $1 \mathrm{~s}$ limit value separating the two domains may be shifted to longer periods, as for instance in urban areas, that are characterized by low frequency and high impedance contrast subsoils. In this case, artificial microtremors may be more energetic than natural microseisms even at intermediate periods up to a few seconds (Beroya et al. 2009).

Since ambient noise measurements can be rapidly performed over large areas, the possibility of linking some features extracted from the background noise recordings to the seismic response of the soil made the ambient noise a suitable tool for many geological studies. Characterization of soil layers (e.g. Delgado et al. 2000), prediction of shear-wave velocity of the ground (e.g. Asten and Dhu 2002; Picozzi and Albarello 2007) and evaluation of the local effects - resonance frequency of the soil and amplification of vibrations during earthquake events (e.g. Zaharia et al. 2008; Bindi et al. 2008; Beroya et al. 2009) are examples of many others. Especially, an important issue seems to be the problem of determining a hazardous of local 
effects, often resulting in tragic consequences in residential areas.

In this paper the possibility of usage of anthropogenic seismic noise (called also cultural noise) for the appointment of amplification factor and resonance frequency of the surface layer in urban areas is presented. Results could be used as a fast tool to shallow geological structure recognition in Upper Silesia Coal Basin. For this purpose, the horizontal-to-vertical spectral ratio (HVSR) method was applied. This method, introduced by Nakamura (1989), is very convenient tool to determine the site effects and based on calculation of the ratio between the Fourier spectra of the horizontal and vertical components of the seismic noise (Zaharia et al. 2008) which were recorded on threecomponents modern seismometer or accelerometer. Observed peak in the $\mathrm{H} / \mathrm{V}$ curve can be correlated with the fundamental resonant frequency and indicate the amplification. Finally, the aim of this study was to estimate the resonance frequency thickness relation $h=h(f)$ where the information about thickness was carried out from seismic measurement. The HVSR curve can produce spurious peaks not associated with the resonant frequency of the ground. Spurious peaks in the site amplification characteristics estimated by $\mathrm{H} / \mathrm{V}$ ratios of microtremors can be generated when ground motion is characterized by negligible spectral amplitudes and instrumental/numerical noise is dominant. Since those HVSR maxima cannot be safely considered as an effect of actual groundmotion characteristics, Albarello (2001) developed a statistical procedure to detect and decrease its influence on final results. In this study we followed with Albarello's statistic test to confirm the proper peak.

\section{The HVSR method}

The H/V technique is simple and allows to get information about dynamic characteristics of ground and structures (Nakamura 2008). The method of $H / V$ spectral ratios, is based on the following hypotheses: 1) the environment consists of a rigid substratum on which a layer of soft soil lie; 2) microtremors are formed of Rayleigh waves. The layer is excited by the ambient noise and the soil transfer function is given by the expression:

$S_{T}=\frac{H_{S}(f)}{H_{B}(f)}$

where:

$H_{S}$ - spectral amplitudes of the horizontal components of microtremors measured at the surface of the soil layer.

$H_{B}$ - spectral amplitudes of the horizontal components of microtremors measured at the bedrock.

This transfer function has a relative maximum at the main resonance frequency of the soil. The signal recorded at a site represents the joint effect of the source, the trajectory of the vibration, and the characteristics of the site. To determine the effect of the soil, the source contribution must first be removed. The $H / V$ ratios method considers that the source spectrum, $S_{s}$, is given by:

$S_{S}=\frac{V_{S}(f)}{V_{B}(f)}$

where:

$V_{s}$ - spectral amplitudes of the vertical components of microtremors measured at the surface of the soil layer.

$V_{B}$ - spectral amplitudes of the vertical component of microtremors measured at the basement.

Dividing (1) by (2) provides us the soil transfer function corrected for the source. A final hypothesis of this method is to assume 
that $\mathrm{H}_{\mathrm{B}} / \mathrm{V}_{\mathrm{B}}=1$. Then, the soil transfer function is:

$$
\operatorname{HVSR}(f)=\frac{S_{T}}{S_{S}}=\frac{H_{S}}{H_{B}} \cdot \frac{V_{B}}{V_{S}}=\frac{H_{S}}{V_{S}} \cdot \frac{V_{B}}{H_{B}}=\frac{H_{S}}{V_{S}}
$$

As a result, the transfer function (HVSR) of a site is given by the spectral ratio of the horizontal and vertical components of microtremors recorded on given point. The great advantage of this technique is that the soil response can be studied with only one station, with no need for an entire array (Nakamura 1989; Delgado et al. 2000; Mendecki 2010).

It is necessary to smooth the spectrum before computing the $\mathrm{H} / \mathrm{V}$ ratio (Konno and Ohmachi 1998). In this paper the smoothing function introduced by $\mathrm{K}$. Konno and $\mathrm{T}$. Ohmachi (1998) was used which enables analysis of HVSR curves obtained from measurements of seismic noise. The KonnoOhmachi based on logarithms of frequencies and allows to determine the smoothed value of the HVSR function:

$$
W_{B}\left(f, f_{c}\right)=\frac{\sin \left[\log _{10}\left(\frac{f}{f_{c}}\right)^{b}\right]}{\log _{10}\left(\frac{f}{f_{c}}\right)^{b}}
$$

where:

b - coefficient for band width,

$\mathrm{f}$ - frequency,

$\mathrm{f}_{\mathrm{c}}$ - center frequency (Konno and Ohmachi 1998).

\section{Albarello statistical test}

It was observed (Albarello 2001) that spurious peaks can be generated in the site amplification characteristics estimated by horizontal-tovertical spectral ratios of microtremors. They are formed because of two reasons. First one, there are present fluctuations of seismic noise that are more or less regular and are connected with periodic human activities (mainly in high frequency ranges). The second one is connected with stochastic fluctuations of apparent spectral amplitudes generated by instrumental or numerical noise (Picozzi et al. 2005).

Due to the stochastic nature of environmental noise, such artifacts could be difficult to recognize by the simple inspection of HVSR patterns, making mandatory creating a specific and reliable processing tools to eliminate, or at least reduce, this problem. An attempt in this direction was carried out by Albarello (2001), who proposed a statistical test able to identify in the HVSR curve maxima that are probably due to purely stochastic fluctuation in the recorded noise (Picozzi et al. 2005).

The aim of this test is to identify spurious peaks induced by instrumental random noise in the case where seismic noise is characterized by small spectral amplitudes (Picozzi et al. 2005). The hypothesis $H o$ assumes that each maximum HVSR may be result of the occurrence of the amplitudes of instrumental random noise. In this test the statistic $k_{m, n}$ can be defined as:

$$
k_{m, n}=\frac{\mu\left(S_{H V}^{2}\right)}{\sigma\left(S_{H V}^{2}\right)}
$$

where:

$\mu\left(S_{H V}^{2}\right)$ - average of the squared spectral ratio HVSR

$\sigma\left(S_{H V}^{2}\right)$ - standard deviation of the squared spectral ratio HVSR

The parameter $m$ is determined by the number of degrees of freedom and it is determined from the relations $m_{i} \cong \operatorname{int}\left\{t \cdot f_{i}\right\}$, where $t$ is the measurement time, $f_{i}$ is the $i$-th frequency. Abbreviation int means the integer 
value of the product. (Albarello 2001; Mendecki 2012).

The next step is to determine the confidence interval of the random variable $K_{m, n}$ ( the set $k_{m, n}$ ) based on the cumulative distribution $P\left(K_{m, n} \leq k_{m, n}\right)$. The confidence interval defined for the upper $k_{m, n}^{u}$ and lower $k_{m, n}^{l}$ limits of statistics as (for the significance level of 0.05 ):

$$
\begin{aligned}
& P\left(K_{m, n} \leq k_{m, n}^{l}\right)<0.025 \\
& P\left(K_{m, n} \leq k_{m, n}^{u}\right)>0.975
\end{aligned}
$$

Distribution values are determined from numerical calculations by the use of pseudorandom number generator in order to achieve adequate levels of $\mathrm{L}=1000$ for the $i$-th degree of freedom and inverse probability distribution function which is used to find the limits of statistics in accordance with the relation (6). For small sample $n$ is applied distribution of $F$-Snedocor (Picozzi et al. 2005). However, according to the Central Limit Theorem for calculation the normal distribution was used, assuming $n=100$ for a large sample.

Taking into account the relations (6) the null hypothesis is rejected at a confidence level of 0.05 if the value of $k_{m, n}$ statistics satisfies the following conditions:

$\left\{\begin{array}{l}k_{m, n}<k_{m, n}^{l} \\ k_{m, n}>k_{m, n}^{u}\end{array}\right.$

Otherwise $H_{0}$ hypothesis cannot be rejected for a $95 \%$ confidence level and then received a maximum HVSR average value for a given $m$ can be considered as a suspect (Albarello 2001; Picozzi et al. 2005).

\section{The resonance frequency - thickness relation}

Considering a sedimentary cover upon a bedrock layer the one can assume it behaves like a filter, amplifying some frequencies and attenuating others. The frequencies, which the maximum amplifications are observed, are called resonance frequencies and the knowledge of such frequencies can provide important information about the superficial layer. If the material is linearly elastic, an hypothesis which is generally acceptable for small deformations, and homogeneous medium, the resonance frequencies $f_{\text {reson }}$ are given by the so called quarter wave law (Delgado et al. 2000, Carniel et al. 2006):

$$
f_{\text {reson }}=\frac{V_{s}}{4 H}=\frac{1}{4 T}
$$

where $V_{s}$ is average shear-wave velocity, $H$ is overburden thickness and $T$ is time taken by a shear wave to reach the top of bedrock. Therefore, the soil resonance frequency changes in the area are an indicator of the bedrock topography. It means that decreasing resonance frequency corresponds to increasing bedrock depth.

A physically plausible $H-f_{\text {reson }}$ relationship can be defined in the assumption that the $V_{S}$ profile in the sedimentary cover has the form:

$V_{S}=V_{s 0}(1+z)^{x}$

where $z$ is the depth, $V_{S 0}$ is the surface S-wave velocity, and $x$ quantifies the rate of increase of velocity with depth (D'Amico et al. 2008). Assuming that the $V_{S}$ profile in the sedimentary cover follows the pattern of equation (9) and a bedrock depth equal to $H$, the time $T$ taken by a shear wave to reach the top of bedrock is (D'Amico et al. 2008):

$T=\int_{0}^{H} \frac{d z}{V_{S}(z)}=\frac{1}{V_{S 0}} \frac{(1+H)^{1-x}-1}{(1-x)}$

and the fundamental resonance frequency form equation (8) yields: 


$$
f_{\text {reson }}=\frac{1}{4}\left[\frac{V_{S 0}(1-x)}{(1+H)^{1-x}-1}\right]
$$

From equation (11), it results that (D'Amico et al. 2008):

$$
H=\left[\frac{V_{S 0}(1-x)}{4 f_{\text {reson }}}+1\right]^{1 /(1-x)}-1
$$

However, shear-wave velocity information is not always available. Another way of obtaining the thickness of overburden is based on assumptions that $H>>1$ and $V_{S O}(1-x)>>$ $4 f_{\text {reson }}$, one has the approximate relation:

$$
H=a\left(f_{\text {reson }}\right)^{b}
$$

where $a$ and $b$ are model parameters. This relation is supported by the observations that

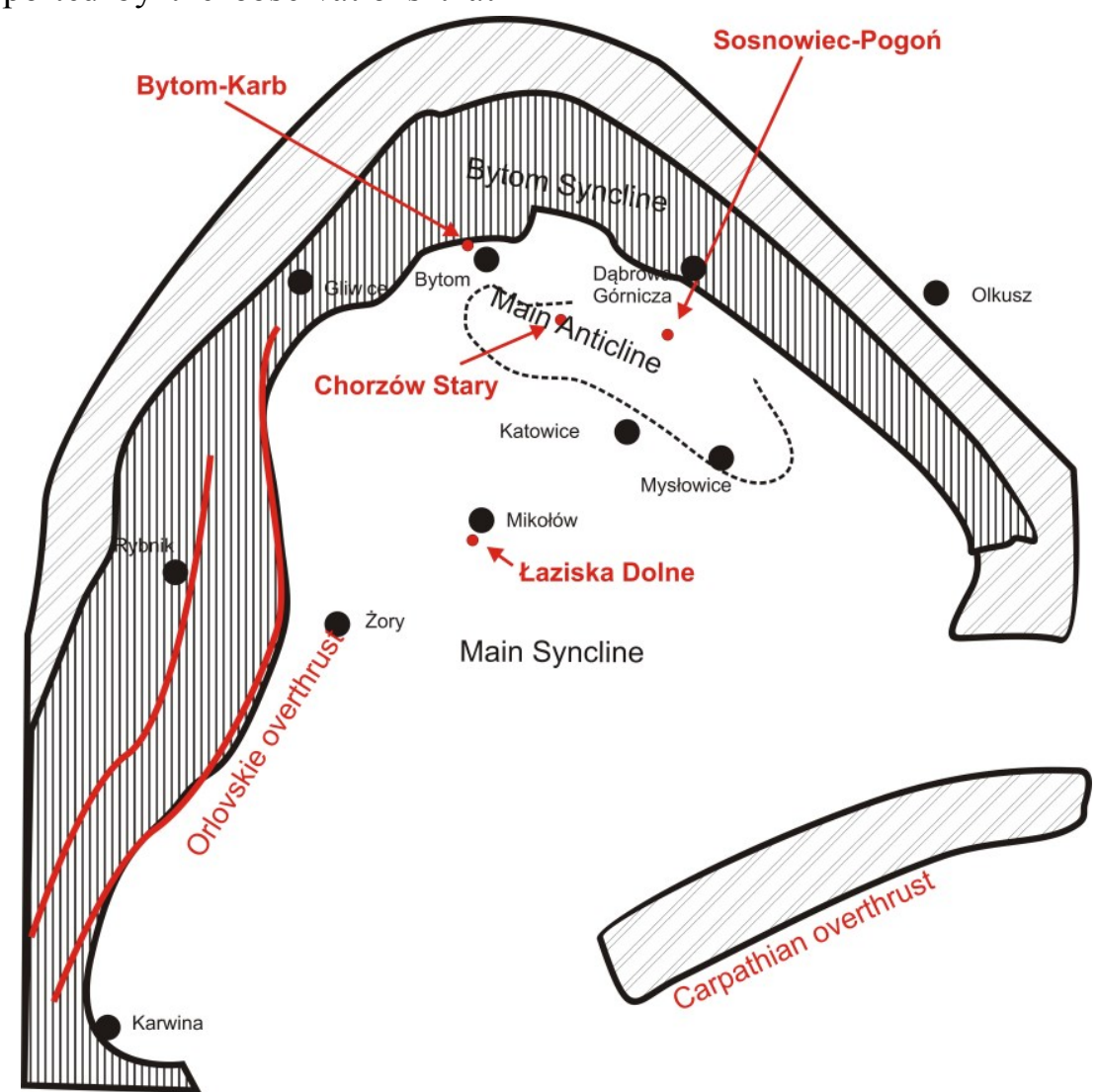

Fig.1. Location of survey sites in Upper Silesia Coal Basin, Poland (based on :

http://www.mincom.home.pl/attachments/Image/zasoby/GZW_szkic_tektoniczny_Korman.jpg) 
Geological data allow to assume that every site is characterized by a relatively simple and typical for the Upper Silesian Coal Basin geological structure - consolidated layers of Carboniferous that lies below unconsolidated sediments (layers of quaternary sands of small thickness). Seismic data were recorded using broadband (frequency range is $0.06 \mathrm{~Hz}-$ $50.0 \mathrm{~Hz})$ three-component seismometer consisted of SP-400 EENTEC seismometer and DR-4000 EENTEC datalogger. The system allows to obtain data with $100 \mathrm{~Hz}$ sampling rates which is sufficient for our analysis.

\section{Processing analysis}

Estimations of local effects parameters were obtained with J-Sesame program (Atakan et al. 2004). This program allows to calculate HVSR curves that give information about amplification factor value corresponding to the resonance frequency of the soil. Each of 30-minute records was divided into 50 time windows of $20 \mathrm{~s}$ length. For every window HVSR curves as well as the mean and standard deviation of each of them were determined. Finally, the resulting HVSR curves were smoothed out by the Konno-Ohmachi technique (Konno and Ohmachi 1998) with a $40 \mathrm{~s}$ length. Each curve was statistically tested using the Albarello test (Albarello 2001) to exclude false peaks in the spectrum caused by instrumental noise or numerical error. The script defining statistics Albarello was written in MatLab programming environment.

\section{Analysis of computing HVSR curves}

After the processing we observed two maxima on the HVSR curve, picked on the basis of Albarello statistical test (Fig.2b), which was estimated from microtremors measurements at Sosnowiec site (Fig.2a). The first peak with amplification equal to 4.1 corresponds to the resonance frequency of $1.0 \mathrm{~Hz}$. The second major peak gives a value of amplification equal to 4.9 and the resonance frequency of 1.5 Hz. Albarello statistics indicates which peak of $\mathrm{H} / \mathrm{V}$ function can be rejected due to hypothesis $H_{0}$. Statistics changes outside of the adopted confidence interval are the basis for the rejection of the hypothesis. In this case, some frequency bands indicates that the HVSR curve is the result of instrumental noise. This bands are between $0.80-0.98 \mathrm{~Hz}$, and $2.7-3.9$; $1.04-$ $1.2 \mathrm{~Hz}$. For the site located in Bytom there were selected one peak in the HVSR spectrum (Fig.3a) based on Albarello statistics (Fig.3b). This peak corresponds to the resonance frequency of $1.8 \mathrm{~Hz}$ with amplification equal to 3.1. In the $\mathrm{H} / \mathrm{V}$ spectrum is the higher peak for frequency equal $1.4 \mathrm{~Hz}(\mathrm{~A}=3.2)$ but in this case $k$ statistics indicate that this might be caused by the maximum random error. In addition, the Albarello's statistical test for almost the entire frequency range is outside the adopted confidence interval, which allows rejection of $H_{0}$ for the whole HVSR curve. Figure 4 shows the H/V spectrum for a sample of field data acquired at Chorzow city. On this curve can be observed distinctive peak at the frequency of $1.25 \mathrm{~Hz}$ with amplification equal to 3.78. However, Albarello statistical test (Fig.4b) indicates that this peak may be caused by instrumental or numerical noise because the test does not allow the rejection of the hypothesis $H_{0}$ at a statistical significance of 0.05 for values in the range from about $1 \mathrm{~Hz}$ to $5 \mathrm{~Hz}$, with few exceptions $(1.35 \mathrm{~Hz}$ to $1.5 \mathrm{~Hz}$, $1.7 \mathrm{~Hz}$ and $2.2-2.4 \mathrm{~Hz}$ ), where $k$ statistic falls below the limit value statistics for $p=0.025$ (Fig.4a). Another words the maximum at $1.25 \mathrm{~Hz}$ was rejected despite it is the highest one. Therefore, the statistical analysis found the next probable maximum at around $2.25 \mathrm{~Hz}$ $(\mathrm{A}=3.1)$. This peak is quite small compared to the surroundings and it is not significantly higher than ambient instrumental noise but it is in area where statistics $k$ allows to reject hypothesis $H_{0}$, so it can be considered as a amplification peak. 

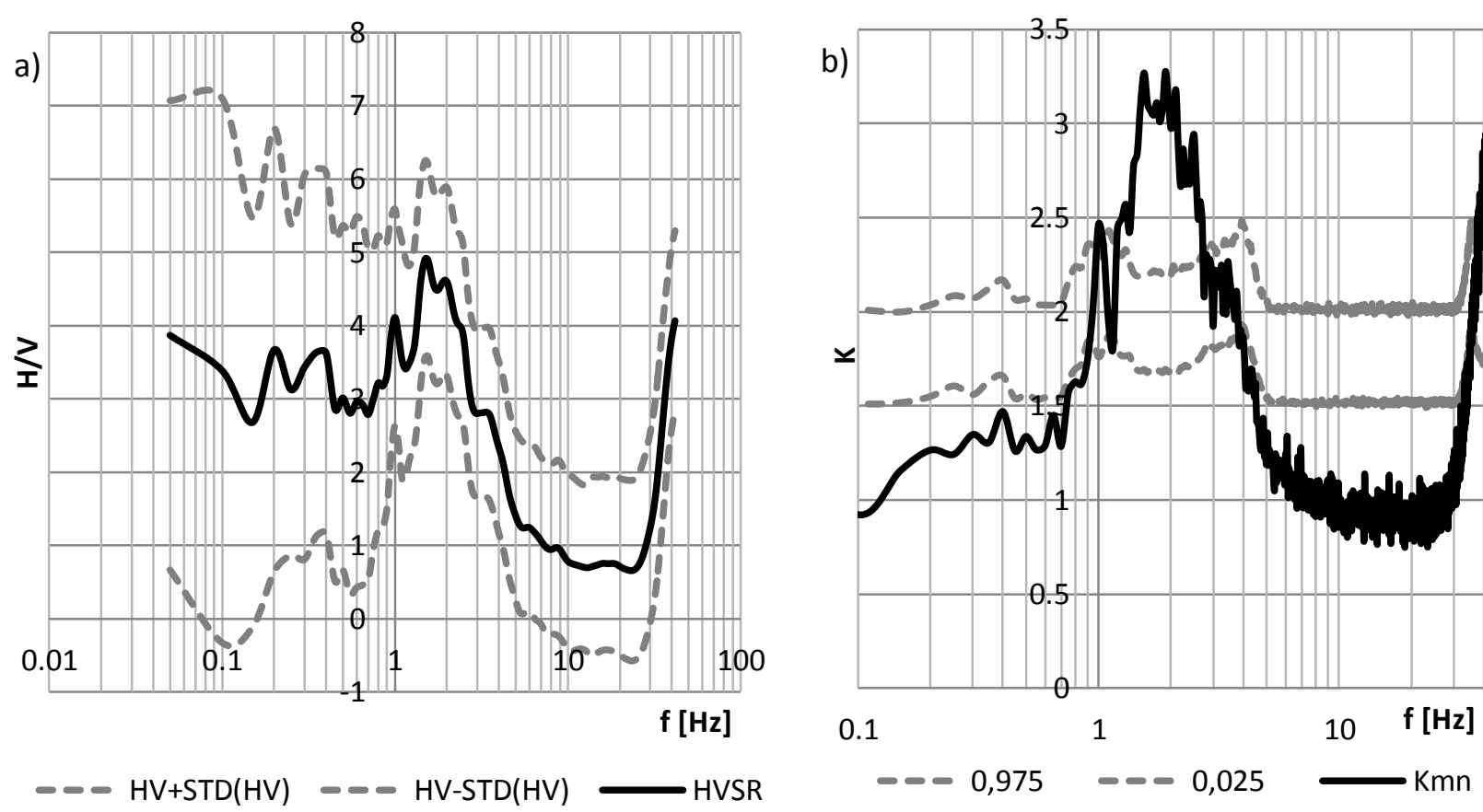

Fig.2.a) HVSR curve estimates from microtremors measurements at Sosnowiec site with its standard deviation gray curves, lower curve represent HV-STD(HV), upper represent $\mathrm{HV}+\mathrm{STD}(\mathrm{HV})$ b) values of the statistic $k$ corresponding to the HVSR values - gray curves, lower curve represent $k(0.025)$, upper represent $k(0.975)$ (Mendecki 2014).

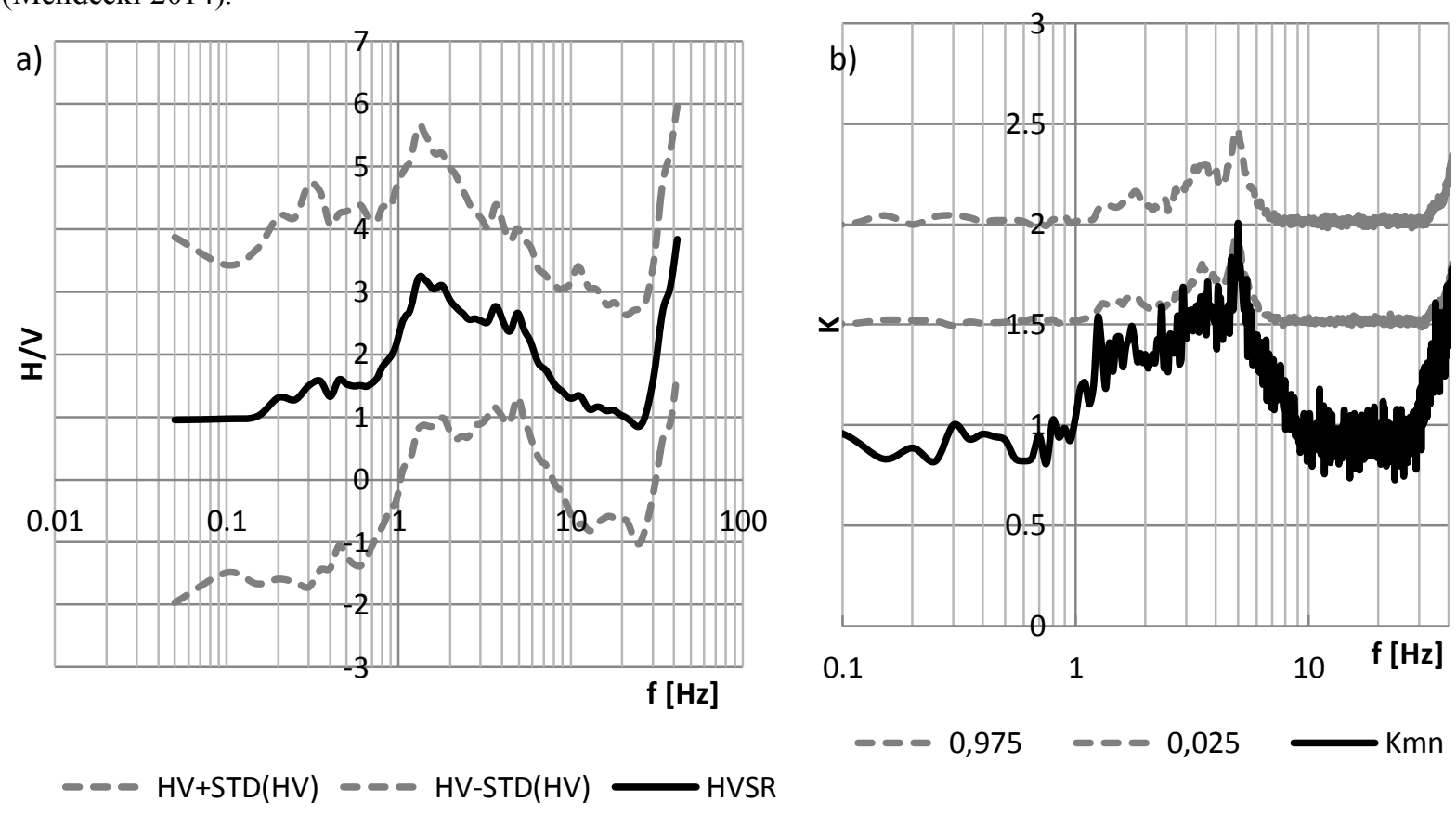

Fig.3.a) HVSR curve estimates from microtremors measurements at Bytom site with its standard deviation gray curves, lower curve represent HV-STD(HV), upper represent $\mathrm{HV}+\mathrm{STD}(\mathrm{HV})$ b) values of the statistic $k$ corresponding to the HVSR values - gray curves, lower curve represent $k(0.025)$, upper represent $k(0.975)$ (Mendecki 2014). 

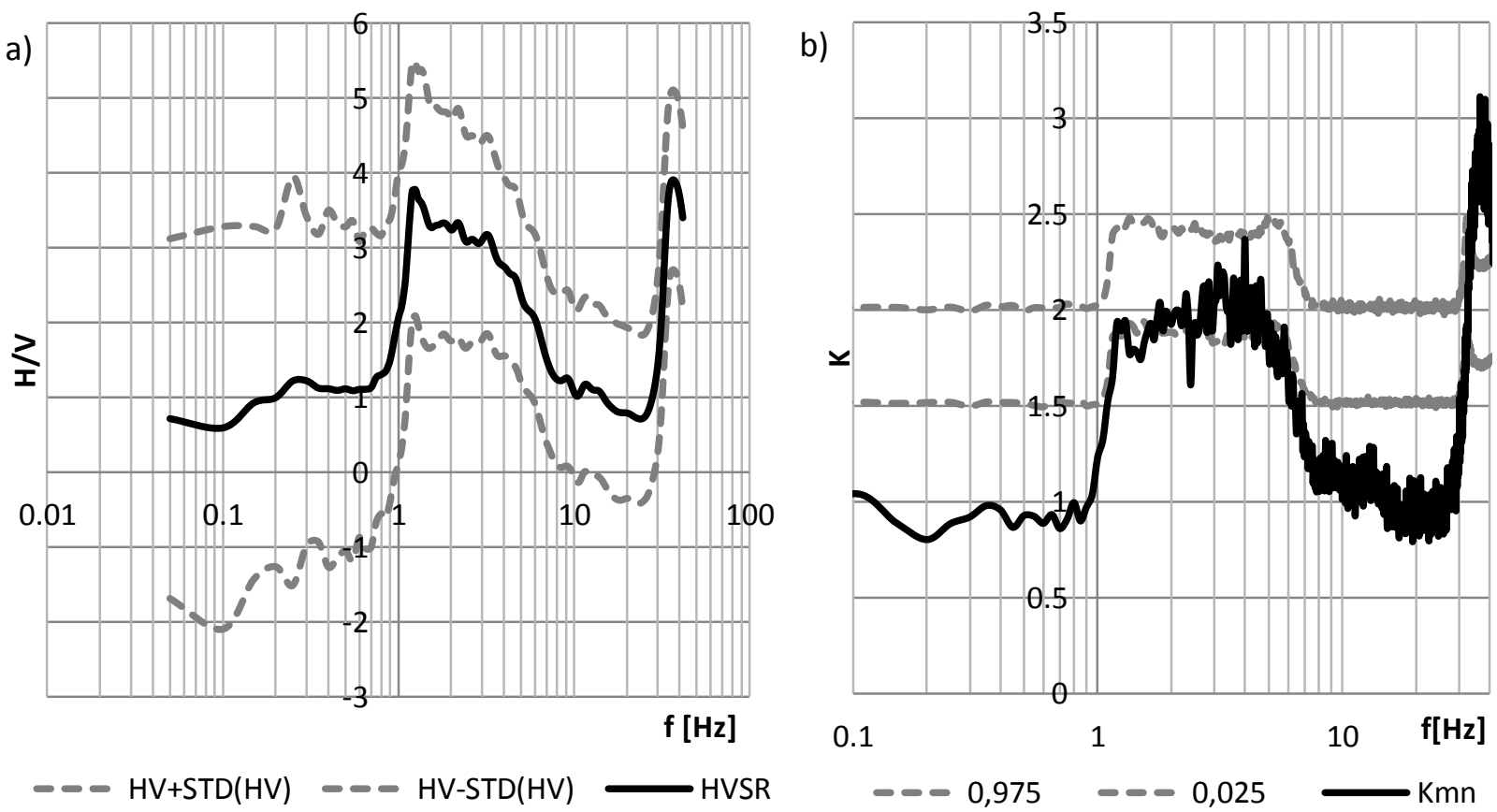

Fig.4. a) HVSR curve estimates from microtremors measurements at Chorzow site with its standard deviation gray curves, lower curve represent HV-STD(HV), upper represent $\mathrm{HV}+\mathrm{STD}(\mathrm{HV})$ b) values of the statistic $k$ corresponding to the HVSR values - gray curves, lower curve represent $k(0.025)$, upper represent $k(0.975)$ (Mendecki 2014).

\section{Discussion and conclusions}

The HVSR method is a tool commonly used in site effect estimation. In this study it was employed to obtain information on the characteristics of subsoils in 3 sites located in Upper Silesia. Such research are the first performed in the USCB area. Using the HVSR Nakamura technique, the predominant frequency and amplification factor at each survey point were determined. All HVSR maxima are located above $1.0 \mathrm{~Hz}$ (Tab.1).

The presented HVSR results indicated that the value of the standard deviation increases for frequencies below $1.0 \mathrm{~Hz}$. This is probably related to the strong wind gusts which were observed during measurement days. According to the instruction of the J-SESAME (SESAME 2004) such increase of the standard deviation can be caused by weather conditions. Application of Albarello statistical test allowed to indicate the maxima, which are not the result of a numerical or instrumental noise.
Due to the assumptions and statistical evaluation, chosen peaks can be interpreted as indicators of local effects in measurement areas.

According to obtained statistical results the selected maxima were assumed as manifestations of local effects occurring beneath the study points.

Beside seismometer measurement on each site Multichannel Analysis of Surface Waves (MASW) with 24 geophone channels connected to a recorder made by PASI company had been applied. Twenty four of 4,5 $\mathrm{Hz}$ geophones were used to record surface waves and seismic noise (Mendecki et al. 2014). The spacing between geophones was 5 $\mathrm{m}$, while the total profile length was $115 \mathrm{~m}$ offset (for active seismic) was in $-5 \mathrm{~m}$ of the profile (Mendecki et al. 2014). The MASW survey allowed to estimate among others thicknesses of Quaternary sediments which were used to calculate the resonance frequency 
- thickness relation. Values of obtained cover thicknesses were presented in Tab.1.

Tab.1. Comparing the resonance frequencies, $f$, and amplification factor, $A$, with measured thicknesses of loose Quaternary sediment, $h$ (Mendecki et al. 2014), determined for the three measurement stations in Sosnowiec, Bytom and Chorzów city.

\begin{tabular}{cccc}
\hline Location & $\boldsymbol{f}[\mathbf{H z}]$ & $\mathbf{A}$ & $\mathbf{h}$ \\
\hline Sosnowiec & 1,5 & 4,9 & 34,7 \\
Bytom & 1,8 & 3,1 & 17 \\
Chorzów & 2,2 & 3,3 & 18 \\
\hline
\end{tabular}

Least-squares method was applied to fit a power law curve to the measuring points. The results are shown in Fig.5. Calculated relation is presented below:

$$
h=59,626 f^{-1,68}
$$

where the coefficient of determination characterizing quality of the fit was $R^{2}=0.66$ and the standard error of estimate SEE $=0.14$. The obtained resonance frequency - thickness relation can be assumed as quite reliable. One can also find that quite similar results can be found in other studies:

$h=55,64 f^{-1,268}$ (Delgado et al. 2000)

$h=58,30 f^{-0,952}$ (Dinesh et al. 2009).

Further research should improve the course of described above relation on the plot. Several studies are planned to expand described relation for the USCB area. This will provide an accurate empirical model which will allow for a quick and non-expansive way of estimating the thickness of loose sediment on the basis of cultural noise measurements in urban areas.

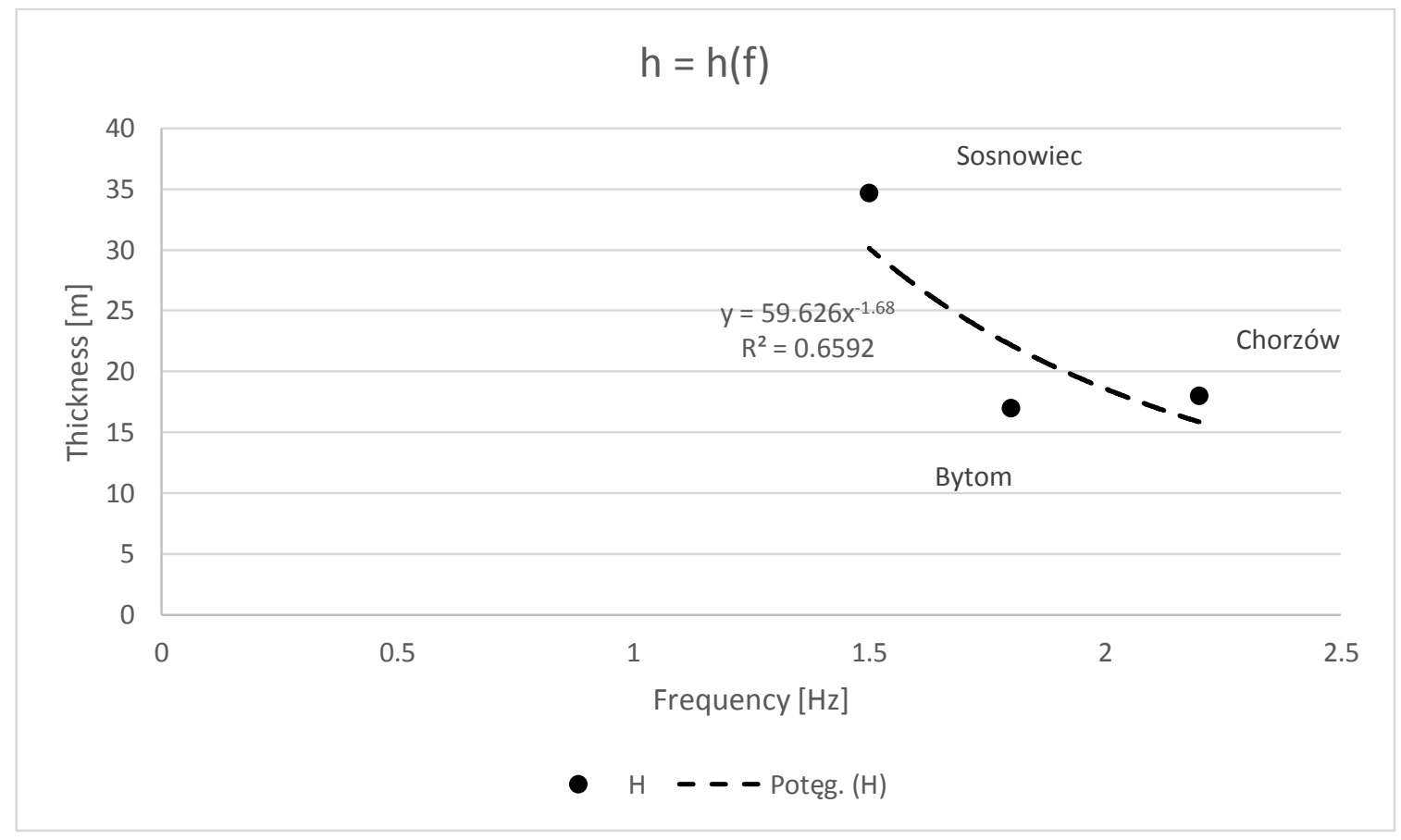

Fig.5. The resonance frequency - thickness relation obtained for measurement points in Upper Silesia Coal Basin, Poland.

\section{Acknowledgments}

The project was partially funded by the National Science Centre granted under Decision No UMO-2012/05/N/ST10/03943 


\section{References}

Albarello D. (2001) Detection of Spurious Maxima in the Site Amplification Characteristics Estimated by the HVSR Technique. Bulletin of the Seismological Society of America, 91, 4, 718-724,

Asten M. W., Dhu T. (2002) Enhanced interpretation of microtremor spectral ratios using multimode Rayleigh wave particle-motion computations,

Atakan K., Duval A-M., Theodulidis N., Bard P-Y., and the SESAME Team (2004) On the reliability of the $\mathrm{H} / \mathrm{V}$ spectral ratio technique. In: D.Doolin, A.Kammerer, T.Nogami, R.B.Seed, and I.Towhata (Eds.). Proceedings of the 11th International Conference on Soil Dynamics and Earthquake Engineering and the 3rd International Conference on Earthquake Geotechnical Engineering, 7-9 January 2004, Berkeley, California, USA, Volume 2, 1-8.

Benjumea B., Macau A., Gabas A., Bellmunt F., Figures S., Cires J. (2011) Integrated geophysical profiles and $\mathrm{H} / \mathrm{V}$ microtremor measurements for subsoil characterization. Near Surface Geophysics, 9, 413-425,

Beroya M. A. A., Aydin A., Tiglao R., Lasala M. (2009) Use of microtremor in liquefaction hazard mapping. Engineering Geology 107, 140-153,

Bindi, D., Marzorati, S., Parolai, S., Strollo, A., Jäckel, K. H. (2008) Empirical spectral ratios estimated in two deep sedimentary basins using microseisms recorded by short-period seismometers. Geophysical Journal International, 176, 1, 175-184,

Carniel R., Barazza R., Pascolo P. (2006) Improvement of Nakamura technique by singular spectrum analysis. Soil Dynamics and Earthquake Engineering, 26, 55-63

D’Amico V., Picozzi M., Baliva F., Albarello D. (2008) Ambient Noise Measurements for Preliminary Site-Effects Characterization in the Urban Area of
Florence, Italy. Bulletin of the Seismological Society of America, 98, 3, 1373-1388,

Delgado J., Lopez Casado C., Giner J., Estevez A., Cuenca A, Molina S. (2000) Microtremors as a Geophysical Exploration Tool: Applications and Limitations. Pure and Applied Geophysics, 157, 1445-1462,

Dinesh B.V., Nair G.J. Prasad A.G.V., Nakkeeran P.V., Radhakrishna M.C. (2009) Relation between sedimentary layer thickness and fundamental frequency of the $\mathrm{H} / \mathrm{V}$ spectra for Bangalore city. Current Science, 97, 7, 1073-1077,

Konno, K. and T. Ohmachi (1998) GroundMotion Characteristics Estimated from Spectral Ratio between Horizontal and Vertical Components of Microtremor. Bulletin of the Seismological Society of America, Vol. 88, No. 1, 228-241,

Mendecki M.J. (2010) Application of ambient seismic noise spectral analysis to determination parameters of site effects for seismic stations located in USCB area. Prace Wydziału Nauk o Ziemi Uniwersytetu Śląskiego, 65, 135-144 (in Polish),

Mendecki M.J. (2014) Związki widma szumu sejsmicznego $\mathrm{z}$ rodzajem i miąższością strefy przypowierzchniowej (Relations between the seismic noise spectrum with the type and thicknesses of surface zone). $\mathrm{PhD}$ thesis, University of Silesia, Katowice (reviewing),

Mendecki M.J., Glazer M., Mycka M. (2014) Application of passive seismic to shallow geological structures in urban areas. Studia Quaternalia. (reviewing).

Nakamura, Y. (1989) A method for dynamic characteristics estimation of subsurface using microtremor on the ground surface. QR of RTR, 130, 25-33,

Nakamura Y. (2008) On the H/V spectrum. The 14th World Conference on Earthquake Engineering Beijing, China, 
Picozzi M., Parolai S., Albarello D. (2005) Statistical Analysis of Noise Horizontal-toVertical Spectral Ratios (HVSR). Bulletin of the Seismological Society of America, Vol. 95, No. 5, 1779-1786,

Picozzi M., Albarello D. (2007) Combining genetic and linearized algorithms for a two-step joint inversion of Rayleigh wave dispersion and $\mathrm{H} / \mathrm{V}$ spectral ratio curves, Geophys. J. Int. 169, 189-200,

SESAME (2004) Guidelines for the implementation of the $\mathrm{H} / \mathrm{V}$ spectral ratio technique on ambient vibrations measurements, processing and interpretations. (Online access:
16.06.2014):

ftp://billy.geo.uib.no/pub/seismo/SOFTW

ARE/SESAME/

USER-

GUIDELINES/SESAME-HV-User-

Guidelines.doc.

Zaharia B., Radulian M., Popa M., Grecu B., Bala A., Tataru D. (2008) Estimation of the local response using the Nakamura method for the Bucharest area. Romanian Reports in Physics, Vol. 60, No. 1, 131-144,

Website (Online access: 16.06.2014): http://www.mincom.home.pl/zasoby.php 